\title{
Erratum to: Poor outcome at 7.5 years after Stanisavljevic quadriceps transposition for patello-femoral instability
}

\author{
Carlo Camathias • Erich Rutz • Marco Götze • \\ Reinald Brunner $\cdot$ Patrick Vavken · Mark S. Gaston
}

Published online: 7 March 2014

(C) Springer-Verlag Berlin Heidelberg 2014

\section{Erratum to: Arch Orthop Trauma Surg}

\section{DOI 10.1007/s00402-014-1947-2}

The original version of this article unfortunately contained a mistake. The affiliation of the third author (Marco Götze) is incorrect. The correct affiliation should be:

Department of Orthopedic Surgery, University Hospital Tübingen, Hoppe-Seyler-Str. 3, 72076 Tübingen, Germany.

The online version of the original article can be found under doi:10.1007/s00402-014-1947-2.

C. Camathias $(\square) \cdot$ E. Rutz $\cdot$ R. Brunner $\cdot$ P. Vavken

Paediatric Orthopaedic Department, University Children's

Hospital Basle (UKBB), Spitalstrasse 33, 4056 Basel,

Switzerland

e-mail: camathias.carlo@gmail.com

M. Götze

Department of Orthopedic Surgery, University Hospital

Tübingen, Hoppe-Seyler-Str. 3, 72076 Tübingen, Germany

P. Vavken

Department of Orthopedic Surgery, Boston Children's Hospital,

Harvard Medical School, Boston, MA, USA

P. Vavken

Harvard Center for Population and Development Studies,

Harvard School of Public Health, Boston, MA, USA

M. S. Gaston

Royal Hospital for Sick Children, Edinburgh, UK 